\title{
LI. On electric insulation in "Vacuum"
}

\section{Lord Kelvin}

To cite this article: Lord Kelvin (1904) LI. On electric insulation in "Vacuum", Philosophical Magazine Series 6, 8:46, 534-538, DOI: 10.1080/14786440409463221

To link to this article: http://dx.doi.org/10.1080/14786440409463221

册 Published online: 15 Apr 2009.

Submit your article to this journal

Џ Article views: 1

Q View related articles $\sqsubset$

4 Citing articles: 3 View citing articles 
distribution of equal density at equal distances from the centre, into which a neutralizing quantum of electrions could be shot and come to rest in such a configuration that, in the presence of other atoms or disturbing electrions, it would aet as Radium does. This is in fact done for the $\beta$ rays of Radium in $\S 13$ above: because the two atoms A, B there put together concentrically may be supposed fixed relatively to one another and called one atom.

\section{On Electric Insulation in "Vacuum" *.} By Lord KeLris †.

$\S 1$. TT has long been well known that difference of electric potential between conductors in a high vacuum is maintained without appreciable current, even when the distance between them is a small fraction of a millimetre. Fifty or sixty years ago, when we had no experimental knowledge of what is now called a high vacuum, it was a vexed question whether vacuum is an insulator or a conductor. In a Royal Institution Friday evening lecture of May 18th, 1860 $\ddagger$, I find that I made the following statement:- "It has been supposed, indeed, that outside the "earth's recognised atmosphere there exists something or "nothing in space which constitutes a perfect insulator ; but "this supposition seems to have no other foundation than a "strange idea that electric conductivity is a strength or a power "of matter, rather than a mere non-resistance."

$\$ 2$. The labour's of many experimenters during the last fifty years, and the comparatively modern atomic theory of electricity, have thoroughly confirmed the view that the sprace of our best modern vacuum, and interstellar and interplanetary space, and generally, space occupied only by the all-pervading luminiferous ether, is a ' $' € v^{\prime} y$ perfect non-resister of electricity passing through it.

$\S 3$. Hence we see that the insulation of electricity in "vacuum" is to be explained, not by any resistance of vacant space or of ether, but by a resistance of glass or metal or other solid or liquid against the extraction of electrions from it, or against the tearing away of electrified fragments of its own substance. The kathode torrent of resinously electrified particles, discovered in 1871 by Varley, rediscovered eight years later by Crookes, and generally accepted as a truth

* By "vacuum" I mean space occupied only by the luminiferous ether.

$\dagger$ Communicated by the Author.

f Sir William Thomson's 'Electrostatics and Magnetism,' §281. 
some eight years later still, has in many discussions and speculations been attributed to the tearing off of portions of the solid metallic kathode. But I believe the most modern and best experiments * tend rather to show that it consists solely or chiefly of atoms of resinous electricity (electrions as I call them).

$\S 4$. However this may be, it is quite certain (if we accept the atomic theory of electricity as true) that the extraction of an electrion from the atom is opposed by a definite permanent force which must be overcome before the electrions can be drawn out. But it may be true, and probably is true in many cases of the loss of resinous electricity from a solid, that the forces called into play may be great enough to tear away the atom, with or without its electrion or electrions, out of its place in the solid. This, however, would not contribute to the transference of electricity from the solid : in other words, Varley's torrent may contain nonelectrified particles, or vitreously electrified particles, along with his negatively electrified particles which we now believe to be atoms of electricity.

$\$ 5$. It is conceivable also that an atom may, by electrostatic force, be extracted from a solid metallic anode : and its electrion or electrions left behind in the anode. In this case the electric current would consist partially, if not wholly, of vitreously electrified particles: but I believe there is no experimental evidence in support of this supposition. Perhaps there is decisive experimental evidence against it. In the case, however, of a liquid anode, or kathode, whether of a non-conductive substance such as oil, or conductive such as liquid mercury or other melted metal, there is a lifting of spray or spindrift from the liquid surface, if the electrostatic force is strong enough: and this gives something of an electric current of vitreously electrified particles from the anode.

$\S 6$. To form some idea of the force required to pluck an electrion out of an atom of the metal of the kathode in a very high vacuum: suppose the vacuum so high that no current, nor torrent of sparks, passes between two bluntended electrodes of thick straight wire, $\frac{1}{48} \mathrm{~mm}$. asunder, when the difference of potential between them is raised to 200,000 volts. The electrostatic force between the middles of their ends will be approximately uniform through the intervening space : and will amount to $96,000,000$ volts per $\mathrm{cm}$.;

* J. J. Thomson, 'Conduction of Electricity through Gases,' $\$ 50$, 279 ; and 'Electricity and Matter,' pp. 86, 87. 
or 320,000 C.G.S. electrostatic. Taking with this J. J. Thomson's most recent estimate * $e=3 \cdot 4 \cdot 10^{-10}$ C.G.S. electrostatic, for the quantity of resinous electricity in an electrion, we find $109 \cdot 10^{-6}$ dyne as the force which a single electrion would experience in the electrostatic field between the electrodes in these circumstances.

$\$ 7$. Consider now a single mono-electrionic atom having a single electrion within it, in equilibrium in the centre of the field. Let $r$ be the radius of the atom, and $x$ the distance from its centre, at which the electrion rests. The electrostatic force at distance $x$ from the centre is $\frac{x}{r} \cdot \frac{e}{r^{2}}$, and therefore if the force of the external field is just sufficient to make $\frac{x}{r}=\frac{1}{y}$, we have $\frac{3 \cdot 4 \cdot 10^{-10}}{9 r^{2}}=320,000$. This gives $r=1 \cdot 1 \cdot 10^{-8}+$.

$\$ 8$. Consider next an equal and similar atom in the extreme front of the kathode. Its electrion will certainly be drawn to a considerably greater distance from its centre than $\frac{1}{9} r$; because it is backed by atoms behind it with their electrions pulled forward : it is probable, however, it could not be quite extracted from the atom without a greater electrostatic force than that considered in $\S 6$. But it seems to me certain, from some imperfect mathematical reckonings which I have made, that from two to four or five times that force would suffice to do so. We shall guess it as $1,280,000$, being four times that force : though the actual amount required is calculable and would certainly be different for different possible crystalline configurations of the molecules in the kathode. 'Thus, merely as an illustration of the orders of the magnitudes concerned, we sball assume that, with $2 \cdot 2 \cdot 10^{-8}$ for the diameter of the atom and $3 \cdot 4 \cdot 10^{-10}$ C.G.S. for the quantity of vitreous electricity in the atom and of resinous in the electrion, an electrostatic force of $1,280,000$ C.G.S. in the ether in front of the kathode would break down the insulation by drawing off electrions from the outlying atoms of the kathode.

§ 9. Leaving atomic considerations for a moment, remark that, per unit area, the outward attraction experienced by a metallic surface under the influence of electrostatic force $\mathbf{R}$ in the air, or the ether, outside is $R^{2} / 8 \pi$. This with $\mathrm{R}=1,280,000$ gives $6.519 \times 10^{7}$ dynes or approximately 66.4 tons weight per square centimetre. The breaking weight of the strongest steel wire scarcely amounts to 20 tons

* 'Electricity and Matter;' p. 78 (1904).

+ See Baltimore Lectures, Lect. xvii. $\$ 80$. 
per square centimetre. Hence the thick straight wire of $\$ 6$ would be broken or would have its electrified end shattered and pulled away in fragments by the electrostatic force suggested at the end of $\S 8$. It would, however, bear without breaking, and possibly withont any disintegration of its electrified end, the 320,000 C.G.S. of $\$ 6$, which would only strain the wire with a force of $16 \cdot 6$ tons weight per square centimetre.

$\$ 10$. Moderate permissible changes in our guess-work assumptions regarding sizes and electric quality of atoms (mono-electrionic or poly-electrionic) might no doubt readily be devised to make the discharge of electrions take place with increasing electrostatic force, before disintegration of either kathode or anode is produced. We have as yet no sure experimental evidence as to what would take place in the perfect vacuum (only ether, no ponderable atoms, in the space between the electrodes) which is our present subject. What has been abserved in respect to the highest of modern vacuums (from one one-millionth to one two-hundred-millionth of an atmosphere by the Macleod gauge), shows tbat a much greater difference of potential than 100,000 volts (which is so far as I know the highest hitherto measured electrostatically) may be maintained between two metallic electrodes without producing a manifest discharge through the "vacuum," even when the electrodes are bronght within less than $1 \mathrm{~mm}$. of contact. And when a discharge does take place it is $I$ believe not generally direct between the nearest points of the ends of the electrodes, but in wildly erratic lateral courses, attributable to residual gaseous inolecules, according to J. J. Thomson's experimental and theoretical investigations on the passage of electricity through gases.

$\$ 11$. In the experiments by which Varley discovered the kathode torrent of resinously electrified particles, the differences ot potential used were those of a Daniell's battery of from 307 to 380 Daniell's elements. The fact that such small electrostatic forces produced luminous discharge, proves that his vacuum was very far from being what is now called a high vacuum: and proves that the molecules of the residual air were largely concerned in all his results. It is exceedingly interesting to learn from J. J. Thomson's experiments of 1897, described in $\$ 50$ of his 'Conduction of Electricity through Gases' that, great though the influence of the residual gas (air or hydrogen or carbonic acid gas) was in respect to the results, the virtual mass of the resinously electrified particle in the kathode torrent is the same for the different gases; and is about 1/770 of that of the hydrogen 
atom ; and is so small that he was led to believe it to be an atom of resinous electricity unloaded with ponderable matter. It is also very interesting to know from J.J. Thomson's experiments and from a continuation of them by H. A. Wilson *, that the virtual mass of the particles of the torrent from the kathode, was the same whether the metal of the kathode was aluminium, platinum, copper, iron, lead, silver, tin, or zinc. This strongly corroborates Thomson's original conclusion that Varley's + "attenuated particles of matter "projected from the negative pole by electricity in all directions," are atoms of resinous electricity.

$\S 12$. It is very much to be desired that careful experiments with the very highest obtainable vacuum should be made to ascertain the greatest steady, measured, difference of potentials; that can be maintained with or without any measurable electric current between two metals separated by a very short length of vacuous space.

LII. On the Stretching and Torsion of Lead Wire beyond the Elastic Limit. By Prof. Troutor, F.R.S., and A. O. Rankine $\ddagger$.

[Plates XIV. \& XV.]

TTHE behaviour of wires or rods when stressed longitu1 dinally or torsionally beyond the elastic limit is of a complicated nature. The general character of the effect: observed on the application of such a stress is as follows. First there is the immediate effect followed by an increase with time. The latter initially may be considerable, but gradually diminishes with time to what appears to be a small constant amount. It is convenient to refer to the first as the primary strain, to the final constant rate as the viscous flow, and the remaining intermediate effect as the secondary strain. What follows refers mostly to the secondary strain.

The method of procedure in investigating this question has apparently always been to apply a constant stress and to observe the rate of change in the resulting strain. Or afterwards to remove the stress and examine the rate of recovery. This method has been adopted for instance in the investigation of torsional strains in wires. We also have used it, but in addition we have used the method in which a constant strain

* H. A. Wilson, Proc. Camb. Phil. Soc. xi. p. 179 (1901).

+ "Some Experiments on the Discharge of Electricity through Rarefied Media and the Atmnsphere," by Cromwell Fleetwood Varley, Proc. R. S. Oct. $5,1870$.

$\ddagger$ Communicated by the Authors. 